\title{
Lesões pulmonares em suínos abatidos no matadouro público municipal de Esperança, Paraíba*
}

\author{
Pulmonary lesionsof slaughtered pigs at the municipal public \\ slaughterhouse of Esperança, Paraíba
}

\author{
Francisca Flávia Silva, ${ }^{* *}$ Ricardo Barbosa de Lucena, ${ }^{* *}$ Temístocles Soares Oliveira Neto, ${ }^{* *}$ Maria Vanuza Nunes Meireles, ${ }^{* *}$ \\ Hermano Manoel Francisco Figueiredo Bezerra, ${ }^{* * *}$ Vinícius Longo Ribeiro Vilela**,***
}

\begin{abstract}
Resumo
O objetivo do presente estudo foi avaliar as lesões macroscópicas e histológicas em pulmões de suínos abatidos no abatedouro público de Esperança, Paraíba. Foram inspecionados pulmões de 180 suínos entre julho e dezembro de 2013. Destes, 34 (18,8\%) apresentaram lesões. Na análise anatomopatológica dos fragmentos coletados, 82,3\% (28/34) exibiram lesões sugestivas de Pneumonia Enzoótica Suína (PES). Seis (17,7\%) amostras apresentaram alterações causadas pela distribuição irregular de sangue. Casos sugestivos de PES crônica foram observados em 57,1\% (16/28) dos fragmentos coletados. Em 42,9\% (12/28) das amostras foram definidos como sugestivos de PES subaguda. Nenhum pulmão apresentou lesões sugestivas de PES aguda. A pesquisa demonstrou que lesões pulmonares em suínos são frequentemente detectadas no abatedouro de Esperança, Paraíba, sendo a maioria destas lesões sugestivas de PES.
\end{abstract}

Palavra-chave: Histopatologia, Inspeção de suínos, Pneumonia Enzoótica Suína.

\begin{abstract}
The objective of the present study was to evaluate the macroscopic and histological lesions in the lungs of slaughtered pigs at the public slaughterhouse of Esperança, Paraíba. Lungs from 180 pigs were inspected between July and December 2013. Lesions were observed in $34(18.8 \%)$ lungs. In the anatomopathological analysis of the collected fragments, $82.3 \%(28 / 34)$ presented suggestive lesions of Swine Enzootic Pneumonia (SEP). Six (17.7\%) samples presented alterations caused by irregular blood distribution. Suggestive cases of chronic SEP were observed in $57.1 \%(16 / 28)$ of the collected fragments. In $42.9 \%$ (12/28) of the samples were defined as suggestive of subacute SEP. No lungs presented lesions suggestive of acute PES. The research showed that lung lesions in pigs are frequently detected in the Esperança, Paraíba slaughterhouse, with the majority of these lesions suggestive for SEP.
\end{abstract}

Keywords: histopathology, swine inspection, Swine Enzootic Pneumonia.

\section{Introdução}

No Brasil, as doenças infecciosas do trato respiratório de suínos se tornaram importantes devido às características dos atuais sistemas de produção, nos quais animais de diferentes origens e fases de produção são criados confinados em um mesmo ambiente. Estes fatores causam estresses e facilitam a disseminação dos agentes (Opriessnig et al., 2011). Segundo Fraile et al. (2010), doenças infecciosas do trato respiratórias geram grandes prejuízos para a suinocultura pelo comprometimento na produção intensiva de suínos em todos os países.

A inspeção Ante e Post-Mortem é de extrema importância para avaliar a saúde dos animais e proporcionar aos consumidores produtos de ótima qualidade. Segundo o RIISPOA (1950), devem ser condenados os pulmões que apresentarem broncopneumonia-verminótica, enfisema, aspiração de sangue ou alimento, outras lesões localizadas, sem reflexo sobre a musculatura.

Durante a inspeção da carcaça, a interpretação das lesões macroscópicas é muito importante para o sucesso do diagnóstico. Algumas alterações pós-mortem podem ser causadas pelo método de eutanásia, estas lesões sem significados são aquelas não importante para causa morte, mas que algumas vezes podem ser confundidas com lesões importantes (Rech et al., 2013).

A Pneumonia Enzootica dos Suínos (PES) ou pneumonia micoplásmica suína é uma doença crônica infecciosa, que tem como agente primário Mycoplasma hyopneumonie. O caráter crônico dessa doença afeta o desenvolvimento do animal, reduzindo a conversão alimentar, o ganho de peso diário e predispondo os animais a infecções secundárias (Thacker, 2006; Redondo et al., 2009).

\footnotetext{
*Recebido em 18 de março de 2017 e aceito em 15 de fevereiro de 2019.

**Programa de Pós-Graduação em Ciência e Saúde Animal, Universidade Federal de Campina Grande - UFCG, Patos-PB.

***Departamento de Medicina Veterinária, Instituto Federal da Paraíba - IFPB, Sousa-PB.

Autor para correspondência: Prof. Vinícius Longo Ribeiro Vilela - vilelavir@yahoo.com.br.
} 
Afeta suínos de todas as idades, sendo que a forma clínica da doença é mais frequente em animais em crescimento e terminação A transmissão ocorre principalmente por meio de aerossóis eliminados no momento da tosse. (Conceição e Dellagostin, 2006; Maes et al., 2008).

Em levantamento realizado em um abatedouro em Saskatchewan, Canadá, durante um período de 12 meses, foram analisados pulmões de 15.409 suínos, onde as lesões macroscópicas sugestivas de PES foram detectadas em $36,7 \%$ dos animais abatidos (Osborne, 1981). Embora pulmões afetados por PES não gerem o desvio ou a condenação de carcaças, em $67 \%$ das carcaças condenadas por lesões pulmonares são encontradas alterações sugestivas de PES, demostrando que esta doença é uma porta de entrada para infecções secundárias (Mores, 2006).

O presente trabalho avaliou a frequência de lesões macroscópicas e histológicas em pulmões de suínos abatidos no matadouro público de Esperança, Paraíba no período de julho a dezembro de 2013. aguda, fase sub-aguda e fase crônica (Santos et al., 2012 ), de acordo com os seguintes critérios morfológicos: hiperplasia linfoide em múltiplos brônquios e bronquíolos, grande quantidade de neutrófilos, macrófagos e linfócitos nos bronquíolos e alvéolos e os septos interlobulares com grande quantidade de fibrina e fibrose pulmonar.

\section{Resultados}

Durante o abate de 180 suínos foram coletadas amostras de 34 $(18,8 \%)$ pulmões com lesões. Na análise anatomopatológica dos fragmentos coletados, $82,3 \%$ (28/34) exibiram lesões sugestivas de Pneumonia Enzoótica Suína, caracterizadas por extensas áreas de hepatização dos lobos pulmonares, que eram firmes à palpação, acinzentadas, entremeadas por áreas marromescuras. No interior de brônquios e bronquíolos havia exsudato amarronzado (Figura 1).
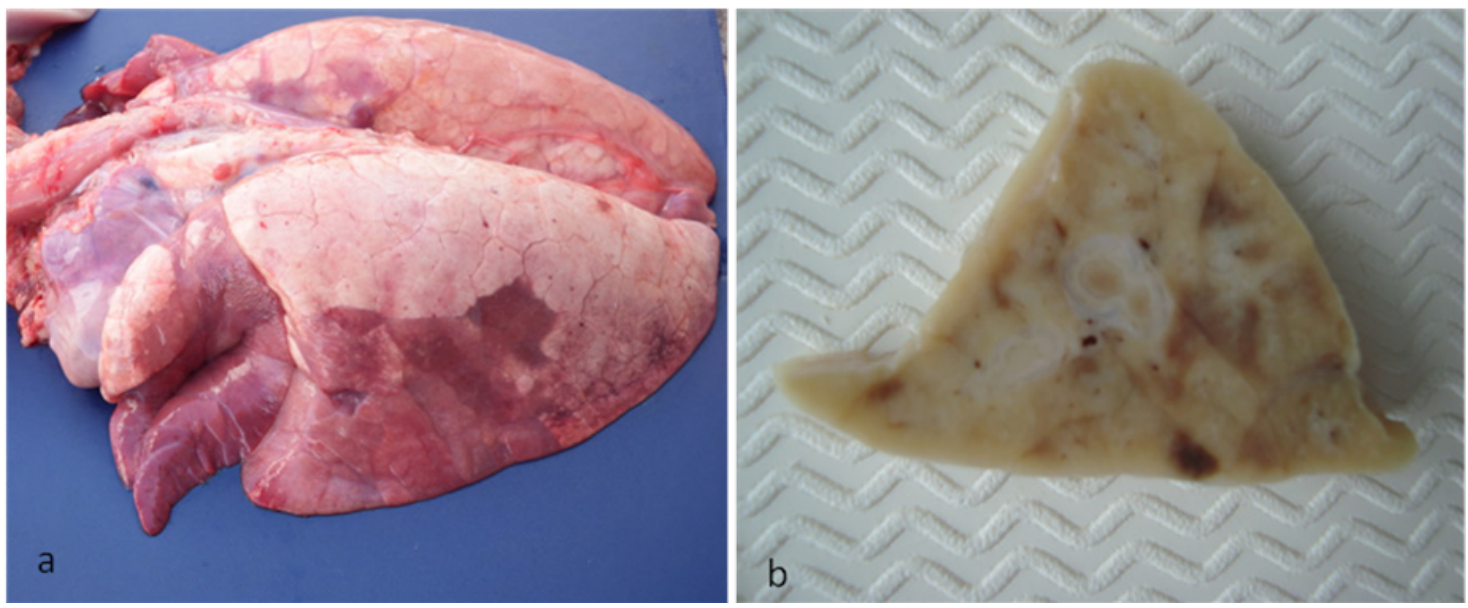

Figura 1: a) Pulmão suíno com acometimento bilateral sugestivo de Pneumonia Enzoótica. b) No interior de brônquios e bronquíolos havia exsudato mucopurulento.

\section{Material e métodos}

As amostras foram coletadas no Abatedouro Público Municipal de Esperança, Estado Paraíba. Durante o período de julho a dezembro de 2013, foram realizadas doze visitas para o acompanhamento do abate de 180 suínos. Foram coletadas amostras de pulmões com lesões sugestivas de Pneumonia Enzoótica Suína (PES) ou qualquer outra alteração. Os pulmões foram avaliados macroscopicamente por inspeção anatomopatológica e os aspectos morfológicos como distribuição da lesão, cor e consistência à palpação foram anotados e classificados de acordo com a área das lesões. Foram coletados fragmentos das lesões de maior extensão, posteriormente eram acondicionados em frascos plásticos, contendo solução de formol a $10 \%$ para o transporte ao laboratório.

O material foi clivado, desidratado em álcool e clareado em xilol para que fossem incluídos em blocos de parafina. Em seguida, era cortado à $5 \mu \mathrm{m}$, montadas as lâminas e coradas pela hematoxilina-eosina de acordo com as técnicas de rotinas. Foram examinados os cortes histológicos em microscópios ópticos e, de acordo com o aspecto microscópico das alterações observadas, foram classificadas conforme a evolução em fase
Em 17,7\% (6/34) foram observadas múltiplas petéquias ou lóbulos marcadamente vermelho-escuros, sugestivo de distribuição irregular de sangue ou aspiração de sangue.

O exame histopatológico revelou diferentes características das lesões. Dentre as amostras com características sugestivas de PES, $57,1 \%$ (16/28) exibiram acentuado espessamento dos septos alveolares e intensa hiperplasia do tecido linfoide peribronquiolar. Por vezes, o tecido linfoide proliferado comprimia e causava obstrução quase total de brônquios e bronquíolos, associada à atelectasia. Na luz de alguns brônquios e bronquíolos, foram observados alguns macrófagos e linfócitos. Estes casos foram definidos como sugestivos de PES crônica. Em 42,9\% (12/28) das amostras, associado aos brônquios e bronquíolos observou-se hiperplasia do tecido linfoide, septos interalveolares espessados por macrófagos e plasmócitos e na luz de brônquios, bronquíolos e alvéolos grande quantidade de neutrófilos, macrófagos espumosos e alguns linfócitos. Estes casos foram definidos como sugestivos de PES subaguda. Nenhum pulmão apresentou lesões sugestivas de PES aguda (Figura 2).

Mesmo apresentado lesões em 34 (18,8\%) pulmões, não houve condenação de órgãos ou fragmentos durante as coletas. 

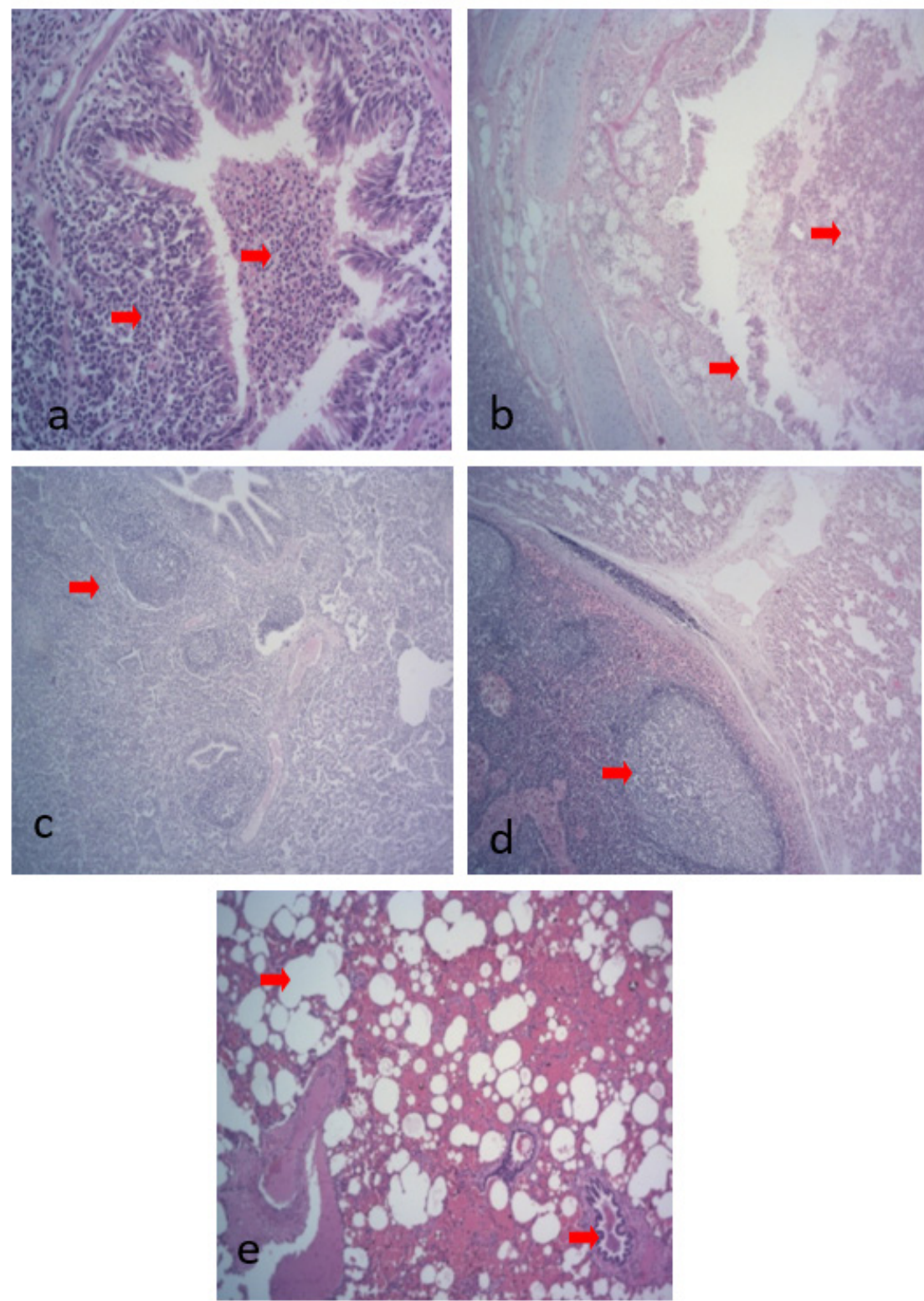

Figura 2: a) Hiperplasia linfoide peribronquiolar do tecido linfoide associada a grande quantidade de infiltrado inflamatório constituído por macrófagos, linfócitos, neutrófilos e fibrina na luz do bronquíolo, obj. 20x, HE. b) Brônquio demonstrando necrose epitelial e grande quantidade de macrófagos, linfócitos, neutrófilos e fibrina em sua luz, obj. 40x, HE. c) Hiperplasia multifocal acentuada do tecido linfoide peribronquíolar, resultado em obliteração da luz de bronquíolos. obj. $4 x, \mathrm{HE}$. d) Maior aumento da imagem observada na figura 3, obj. 40x, HE. e) Alvéolos e bornquilos difusamente preenchidos por eritrócitos, caracterizando um caso de aspiração de sangue durante o abate do suíno, obj. 10x, HE.

\section{Discussão}

As características macroscópicas observadas foram caracterizadas por áreas de consolidação bem delimitadas, acrepitantes, de aspecto carnoso, vermelhas localizadas nos lobos apicais, cardíacos e intermediários (distribuição crânio-ventral), bem como presença de exsudato catarral, mucopurulento ou purulento, são consideradas características de PES (Hurnik et al.,1993). Essas alterações também podem estar presentes com menor frequência na porção cranial dos lobos diafragmáticos (Oboegblulen, 1981; Maes et al.,1996).
Em relação ao seu aspecto macroscópico e microscópico, a PES pode apresentar-se com vários graus de severidade, em decorrência de fatores como idade em que o suíno se infectou e em qual fase da enfermidade esse suíno foi abatido. Andreasen et al. (2001), evidenciaram em estudo experimental que as lesões pulmonares mais extensas eram observadas em suínos que realizaram soroconversão em poucas semanas antes do abate.

O elevado percentual de pneumonia indica a importância das infecções transmitidas pela via aerógena consequentes de doenças fúngicas e micobactérias (Mcgavin; Zachary, 2007), provavelmente favorecidas pelas condições de higiene das 
instalações nas propriedades suinícolas das quais os suínos eram provenientes. As lesões de caráter infeccioso encontradas neste estudo foram sugestivas para Pneumonia Enzoótica Suína, uma das mais importantes doenças respiratórias em suínos, diferindo de D'Alencar et al. (2011), que observaram principalmente Pneumonia Granulomatosa em suínos, numa pesquisa realizada na Região Metropolitana de Recife e Zona da Mata de Pernambuco.

O sistema de manejo adotado nas propriedades de onde os suínos do presente estudo eram provenientes não pode ser totalmente investigado. No entanto, a maioria dos animais pertencia a propriedades não tecnificadas e de baixo controle sanitário. Algumas pesquisas observaram que os surtos de PES em sistemas intensivos de criação de suínos são mais severos que os observados antigamente e seu nível de intensidade não depende apenas da presença do $M$. hyopneumoniae, mas também do conjunto de fatores de risco que causam baixa na imunidade. Sendo assim, existe uma alta probabilidade de ocorrência de afecções pulmonares graves quando se observam as seguintes condições: densidade superior de 15 suínos por baia, ausência de um vazio sanitário da sala entre os lotes, excessiva quantidades de moscas, entre outros (Santos et al., 2012).

$\mathrm{Na}$ análise anatomopatológica das 34 amostras de pulmões com lesão, 82,3\% (28/34) apresentaram lesões características de PES e 17,7\% (6/34) exibiram alterações circulatórias. Em um estudo realizado com suínos no município de Alagoinhas na Bahia $53,64 \%$ dos pulmões apresentavam pneumonia, seguida de $35,23 \%$ de lesões por aspiração de sangue e 9,66\% apresentaram pleurite (Costa et al., 2014).

\section{Referências}

ANDREASEN, M.; MOUSING, J.; THOMSEN, L. K. No simple association between time enlapsed from seroconversion until slaughter and the extent of lung lesions in Danish swite. Preventive Veterinary Medicine., v.52, p.147-161,2001b.

BRASIL. Ministério da Agricultura Pecuária e Abastecimento. Secretaria de Defesa Agropecuária. Departamento de Inspeção de Produtos de Origem Animal. Regulamento da Inspeção Industrial e Sanitária de Produtos de Origem Animal (RIISPOA). Aprovado pelo decreto n.30.691, 29/03/52, alterados pelos decretos n.1255 de 25/06/62.

CONCEIÇÃO, F.R.; DELLAGOSTIN, O.A. Etiopatogenia e imunoprofilaxia da pneumonia enzoótica suína. Cienc. Rural, v.36, p.1034-1042, 2006.

COSTA, R. A.; LEITE, P. A, G.; BARROS, C. G. G. B.; LOPES, G. $M$. B. principais causas de condenações em vísceras comestíveis de suínos abatidos em um matadouro frigorífico sob inspeção estadual na região de alagoinhas-Ba. Vet. e Zootec, 21(4), p. 616-623, 2014.

D'ALENCAR, A. S.; FARIAS, M. P. O.; ROSAS, E. O.; LIMA, $M$. $M$ et al. Manejo higiênico-sanitário e lesões pulmonares em suínos na Região Metropolitana de Recife e Zona da Mata de Pernambuco, Brasil. Semina: Ciências Agrárias, Londrina. V 32, n 3, p. 1111-1122, 2011.

FRAILE, L.; ALEGRE, A.;LÓPEZ-JIMÉNEZ, R.; NOFRARÍAS, M. \& SEGALÉS, J. Risk factors associated with pleuritis and crânioventral pulmonar consolidation in slaughter-aged pigs. Vet. J. 184:326-333, 2010.
A avaliação macroscópica mostrou-se boa indicadora da Pneumonia Enzoótica Suína (PES) no presente estudo. Porém, mesmo que as lesões macroscópicas sejam sugestivas de PES, elas não são patognomônicas, uma vez que outros organismos, como o vírus da influenza suína ou infecções por bactérias podem produzir lesões semelhantes (Pijoan, 1999; Palzer et al., 2008). Além disso, lesões em resolução podem ser confundidas com lesões recentes de infecção por $M$. hyopneumoniae na linha de abate (Livingston et al., 1972; Sorensen et al.,1997). Porém, a avaliação histopatológica foi fundamental para o diagnóstico da PES.

Embora a presença de lesões histológicas sugestivas de $M$. hyopneumoniae seja considerada como diagnóstico da infecção, já houve a detecção do patógeno em animais sem lesões histopatológicas (Sorensen et al., 1997).

Diante da realidade demonstrada com os resultados obtidos, algumas medidas profiláticas podem ser adotadas nas propriedades e nos abatedouros, visando minimizar os prejuízos causados pelas perdas nos rebanhos, através de práticas simples como a desinfecção e vazio sanitário; separação dos animais recém-adquiridos, além de desmame precoce, condenação dos pulmões lesionados e a capacitação dos trabalhadores envolvidos.

\section{Conclusão}

O presente estudo demonstrou uma alta frequência de lesões sugestivas de Pneumonia Enzoótica em suínos abatidos em Esperança, Paraíba

HURNIK, D.; HANNA, P. E.; DOHOO, I .R. Evaluation of Rapid Gross Visual Appraisal of swine lungs at slaughter as Diagnostic secreen for Enzootic Pneumonia, Can. J. Vet. Res. V. 57. N.1 p. 37-41. 1993.

LILJEGREN, C. H.; AALBAEK, B.; NIELSEN, O. L.; JENSEN, $H$. E. Some new aspects of the pathology, pathogenesis, and etiology of disseminated lung lesions in slaughter pigs. Acta Pathologica Microbiologica et Immunologica Scandinavica, v 111, p. 531-538, 2003.

LIVINGSTON, C.W.; STAIR, E.L.; UNDERDAHL, M.S.; MEBUS, C.A. Pathogenesis of Mycoplasma Pneumoniae in Awine. Am. J. Vet. Res., 33, p. 2249-2258, 1972.

MAES, D.; SEGALES, J.; MEYNS, T. et al. Controlo f Mycoplasma hyopneumoniae infections in pigs. Vet. Microbiol., v.126, p.297309, 2008.

McGAVIN, M. D.; ZACHARY, J. F. (Ed.). Pathologic basis of veterinary disease. $4^{\text {th }}$ ed. St. Louis, Missouri: Elsevier Mosby Saunders, 2007.

MORÉS, M.A.Z. Anatomopatologia e bacteriologia de lesões pulmonares responsáveis por condenação de carcaças de suínos nos matadouros.2006. Dissertação (Mestrado em Ciências veterinária)-Programa de Pós-graduação em ciências veterinária, Universidade Federal do Paraná, Cuiabá.

OBOEGBULEN, S. I. Enzootic Pneumonia of Pigs: A Review. Bull. Aim. Hith. Prod. Afr, v. 29, n. 3, p. 269-274, 1981.

OPRIESSNIG, T; GIMÉNEZ-LIROLA, L.G. \& HALBUR, P.G. Polymicrobial respiratory disease in pigs. Anim. Health. Res.Rev. 12: 133-148, 2011. 
PALZER, A.; RITZMANN, M.; WOLF, G.; HEINRITZI, K. Associations between pathogens in healthy pigs and pigs with pneumonia. Veterinary Record 162, 267-271, 2008.

PIJOAN, C. Pneumonic pasteurellosis. In: Straw, B., D’ Allaire, S., Mengeling, W.L., Taylor, D.J. (Eds.), Diseases of Swine. lowa University press, lowa, p. 511-521, 1999.

$\mathrm{RECH}, \mathrm{R}$. R. et al. Nem tudo que parece ser, é lesão: aspectos anatômicos, não lesões, artefatos, lesões sem significados clínico e alterações post mortem encontrados na necropsia de suínos domésticos e selvagens. Pesquisa veterinária Brasileira, Concórdia, v. 33, n.10, p.1237-1255,2013.

REDONDO, E., MASOT, A.J., FERNÂNDEZ,A.,GÁZQUEZ, A.

Histopathological and immunohistochemical findings in the lungs of pigs infected experimentally with mycoplasma hyopneumoniae. Journal of Comparative Pathology, V.140, P. 260-270, 2009.
SANTOS, J. L. et al. Doenças do suínos. 2 ed. Goiânia: cânone editorial, 2012, 959 p.

SORENSEN,V.; AHRENS,P.; BARFOD,K.; FEENSTRA,A.A. et al. Mycoplasma hyopneumoniae infection in pigs: Duration of the disease and evaluation of four diagnostic assays. Veterinary Microbiology, v. 54, p.23-34, 1997.

THACKER, E.L. Mycoplasmal diseases . In: STRAW, B.E et al. Diseases of swine. 9. ed.Australia: Blackwell Publishing . 2006. Cap 42. P. 701-717, 2006. 